\title{
Relations between Different Dimensions of Self-Perception, Self-Esteem and Body Mass Index of Female Students
}

\author{
Relaciones entre las Diferentes Dimensiones de la Autopercepción, \\ Autoestima e Índice de Masa Corporal de Mujeres Estudiantes
}

Vesna Bratovcic"; Branimir Mikic ${ }^{* *}$; Zarko Kostovski***; Amela Teskeredzic* \& Izudin Tanovic ${ }^{* * * * *}$

BRATOVCIC, V.; MIKIC, B.; KOSTOVSKI, Z.; TESKEREDZIC, A. \& TANOVIC, I. Relations between different dimensions of self-perception, self-esteem and body mass index of female students. Int. J. Morphol., 33(4):1338-1342, 2015.

SUMMARY: The aims of this study were to investigate the association of body mass index with different dimensions of selfperception and the level of self-esteem among female students of first and second year at the University of Tuzla. The study was conducted on a sample of 120 female students of the first and second year at the University of Tuzla. The study used the following instruments: Rosenberg Self-Esteem Scale (ROSF), Questionnaire PD/form A and Body Mass Index calculation. Results indicate that self-esteem and self-worth, and a sense of comfort and discomfort affect the experience of body perception unrelated to body mass index. It is also determined which variables are significant predictors of the experience of body perception and the level of self-esteem in the examined sample. The obtained results indicate a significant correlation between self-perception and sense of well-being related to body image on self-esteem among students in the study sample, which may not be related to actual body appearance in terms of reduced or increased body weight.

KEY WORDS: Self-perception; Body mass index; Self-esteem; Students.

\section{INTRODUCTION}

General physical appearance and the appearance of certain parts of the body during puberty drastically change in the relatively short time that the look becomes one of the main concerns of young people. This concern is related to the social norms and cultural models on the preferred physical appearance that affect the perception of their own bodies.

A significant contribution to body perceptions provides body weight. Concern about overweight is higher in girls than in boys, but both sides have estimated that obesity negatively affects their social standing among peers (O'Dea \& Abraham, 1999; Pritchard et al., 1997).

The body perception is one of the components of the self concept (Lackovic-Grgin, 1994) that reflects the perception, thinking and feelings of a person related with the body and bodily experiences. The cognitive component of body image involves focus of attention on the body and the related statements and the opinion about body and bodily experiences. Emotional component includes experiences of pleasure or discomfort, satisfaction or dissatisfaction associated with the appearance as well as a variety of body experiences. Slade (1994), based on a series of studies in this area, tried to identify the factors that influence body perception. He defines it as unstable mental representation of the body that depends of at least seven factors: a) Previous sensory experiences related to body, b) Current changes in body weight, c) Cultural and social norms, d) Individual attitudes related to body, e) Cognitive and affective variables, f) Individual psychopathology and g) Biological variables.

Rosenberg et al. (1995) defines self- esteem as "totality of the individual's thoughts and feelings with reference to himself as an object." The perception of body has a significant share in the overall self-concept, and general self-esteem.

\footnotetext{
* Faculty of Education and Rehabilitation, University of Tuzla, Tuzla, Bosnia and Herzegovina.

** Faculty of Science and Education, University of Mostar, Mostar, Bosnia and Herzegovina.

**** Faculty of Physical Education Sport and Health, Ss. Cyril and Methodius University, Skopje, Republic of Macedonia.

***** European University, Brcko, Bosnia and Herzegovina.
} 
Importance of body look for design of physical selfconcept, and development of a general self-concept is great because it is the body, especially with regard to the evaluation of others, the first that the others observe in communication. The body is the most visible part of the individual always exposed to others. The fact that in Western culture the stereotype associated with beauty is slender and skinny body supports the use of various diets amongst girls who are insecure in their own identity and are particularly worried about someone else's evaluation. For most of these girls cultural ideal of beauty is elusive, and after many failed attempts to achieve it, they develop low self-esteem. Incompatibility between levels of body weight and medical and cultural recommendations for weight loss can result with difficulties in maintaining or losing weight, but it can result in variations in physical standards too. In some people it can simply result with disordered self-perception of ideal body weight that is different from health and cultural standards (Chang \& Christakis, 2003). A series of studies has shown that a general sense of self-esteem is closely linked to satisfaction with body. Pokrajac-Bulian \& Zivcic-Becirevic (2005) in their paper used Body Shape Questionnaire and the Croatian version of the Rosenberg Self-Esteem Scale, and the results show a significant negative correlation of body image dissatisfaction and self-esteem, and a significant contribution to the body shape dissatisfaction to self-esteem.

Klaczynski et al. (2004) in their paper, used a Questionnaire of satisfaction with body appearance and Rosenberg Self-Esteem Scale, and received a positive correlation between satisfaction with body image and selfesteem. The objectives of this study were to investigate the association of body mass index with different dimensions of self-perception and body image and self-esteem among female students of first and second year at the University of Tuzla. Also, the goal of this paper is to determine which variables were significant predictors of the better body perception and the level of self-esteem in the sample.

\section{MATERIAL AND METHOD}

The sample of respondents is conducted from 120 female students of the first and second year of University in Tuzla.

The process of testing and assessment instruments includes measuring height and body mass, as well as testing students, in order to collect data on self-perception and selfesteem, and were performed during the summer semester of 2012/13 school year. All respondents were voluntarily engaged in research.
Rosenberg Self-Esteem Scale - RSES. Rosenberg (1965) constructed Self-Esteem Scale which shows the overall picture of positive or negative attitudes towards themselves, the global self-esteem, which is composed of related aspects of self-perception. Scale has been validated on a large sample of high school students, and consists of 10 claims of which five were defined in a positive direction, and five in the negative. Higher score indicates more self-esteem, and the results are in the range of 10 to 40 .

Questionnaire PD / Form A (Prstacic \& Hrastovec, 2003). The questionnaire is intended to identify coping mechanisms based on the controlled variables in the following areas: body perception, body image, body image color gram, body position preferences, etc. The application of this instrument investigated next self-dimension: body perception (DOZT), satisfaction ("I feel good" - OSDO) and dissatisfaction ("I feel poorly" - OSSL) related with body image. Respondents were told that in the modified visual-analogue scale from 0 to 100 self-determine the value of the intensity of the experience of these dimensions. They were instructed to submit thoughts and feelings that dominated their perception when you thought about the mentioned dimensions.

Body Mass Index - BMI. On the basis of data on weight and height body mass index (BMI) was determined. It is an objective measure that can determine whether a person is by their weight in relation to height, average, or, more or less below/above average. Body mass index is calculated by dividing the weight expressed in kilograms by the square of body height in meters. World Health Organization criteria for the assessment of the nutritional status based on the value of BMI in adults (except pregnant women) are: i) below 18.5= underweight, ii) 18.5 to $24.9=$ desirable weight, iii) 25.0 to $29.9=$ increased weight, iv) 30.0 to $34.9=$ grade I obesity, v) 35.0 to $39.9=$ grade II obesity an vi) above $40=$ grade III obesity

The methods of data processing that were applied in this research are the following mentioned: Frequencies for the variables were calculated. The correlation between the studied variables was calculated by using Pearson's correlation coefficient. Influence of body mass index and self-perception on the dimension of self-esteem, and the influence of self-esteem, body mass index and dimensions of self-perception on the dimension of the experience of the body were examined using regression analysis.

\section{RESULTS AND DISCUSSION}

The frequency of results for variable BMI. Table I show that in this sample the majority of subjects had a normal 
body weight (84\%), but a significant number of respondents, considering their chronological age, are malnourished (10\%) and have increased body weight (12\%).

Table I. Body Mass Index values in the sample.

\begin{tabular}{lcc}
\hline BMI & n & $\mathbf{\%}$ \\
\hline Underweight & 12 & 10.0 \\
Desirable weight & 84 & 70.0 \\
Increased weight & 14 & 12.0 \\
Grade I obesity & 10 & 8.0 \\
\hline
\end{tabular}

The frequency results for the variable self-esteem (RSES). As Table II shows, all the subjects on Rosenberg's self-esteem scale achieved the results in the range of 20-40 points, which is a normal level of self-esteem. None of the subjects had less than 20 points on a scale of self-esteem.

Table II. Rosenberg Self-Esteem Scale values.

\begin{tabular}{lcc}
\hline RSES & n & \% \\
\hline $10-20$ & 0 & 0 \\
$21-30$ & 48 & 40 \\
$31-40$ & 72 & 60 \\
\hline
\end{tabular}

The frequency results for the variable "Body perception"(DOZT). Figure 1 show that at the visualanalogue scale, body perception, most of the results grouped around values between 55 and 75 (45\%), and values between 80 and $100(33 \%) .13 \%$ of them had scores 50 and $9 \%$ of the valued perception of their bodies below 50 (low level of self-perception).

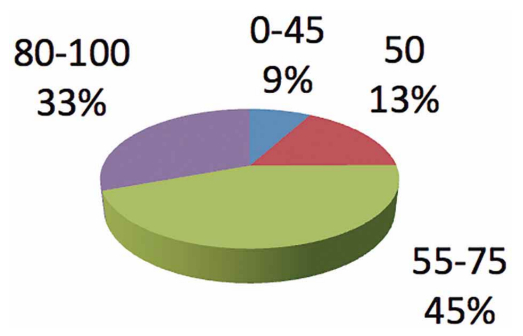

Fig. 1. The frequency of results for the variable "Body perception" (DOZT).

The frequency of results for the variable "I feel good" (OSDO). Figure 2 shows that at the visual-analogue scale, self-perception of the dimension feeling good, most of the results grouped around values between 80 and 100 (61\%), and values between 55 and 75 (31\%). Six percent of them had scores 50 , and $2 \%$ of participants graded dimension "feel good" with a score from 0 to 45 (low level of experience).

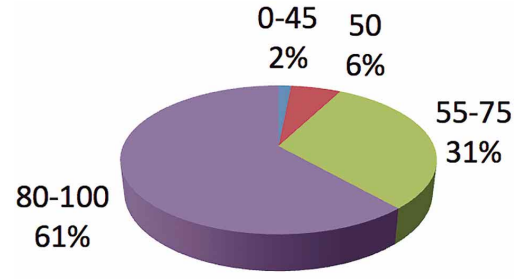

Fig. 2. The frequency of results for the variable "Feel good" (OSDO).

The frequency results for the variable "I feel poorly" (OSSL). Figure 3 shows that at the visual-analogue scale, self-perception of dimension "I feel poorly" most of results grouped around values between 0 and $45(51 \%)$ and the value of $50(23 \%)$. Fourteen percent of respondents assessed dimension feeling poorly with values 55 to 75 . Twelve percent of them rated the discomfort with scores 80 to 100 .

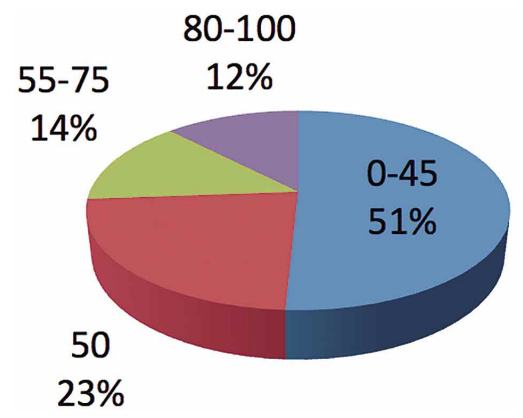

Fig. 3. The frequency results for the variable "I feel poorly" (OSSL).

Results of correlation analysis for the observed variables. Table III shows that the variable body mass index achieved a statistically significant negative correlation with the variables "I feel good" and "body perception". Variable "self-esteem" was significantly positively associated with variables "I feel good" and "body perception", and achieved a negative correlation with a variable "I feel poorly".

During self-perception of dimension "I feel poorly", "I feel good" and "body self-perception" female respondents had obtained a total of 439 induced thoughts - words. Table IV presents those words. Analysis of the results shows that self-perception of dimension "I feel poorly" and "I feel good" dominated by thoughts such as: fatigue, faculty, exams, happiness, pleasure, love. Those thoughts were not related to the physical appearance, there are induced by other sources of worry and pleasure. When thinking about the dimension of the experience of the body dominant thoughts were: good looking, pretty, nice, which are directly related to expectations of external evaluators, and not to actual size of body. That may explain negative correlation between "body perception" with "body mass index" and positive correlation between "body perception" and "self-esteem" (Table III). 
Table III. Correlation between Body Mass Index and different dimensions of self - perception and self-esteem of female students.

\begin{tabular}{lccccc}
\hline & BMI & RSES & OSSL & OSDO & DOZT \\
\hline BMI & 1.00 & -0.35 & 0.16 & -0.32 & -0.61 \\
RSES & -0.14 & 1.00 & -0.31 & 0.35 & 0.44 \\
OSSL & 0.16 & -0.31 & 1.00 & 0.07 & -0.27 \\
OSDO & -0.29 & 0.34 & 0.07 & 1.00 & 0.51 \\
DOZT & -0.59 & 0.44 & -0.28 & 0.51 & 1.00 \\
\hline
\end{tabular}

Body Mass Index (BMI), Self-esteem (RSES), I feel poorly (OSSL), Body perception (DOZT), I feel good (OSDO).

Table IV. Dominant thoughts and feelings induced during self -perception of dimensions "I feel good", "I feel poorly" and "body perception".

\begin{tabular}{llcc}
\hline Dimensions & Dominate thoughts and feelings & n & f \\
\hline I feel poorly & Fatigue & 59 & $45.03 \%$ \\
& Exams & 36 & $27.48 \%$ \\
\multirow{3}{*}{ I feel good } & Faculty & 36 & $27.48 \%$ \\
& Happiness & 76 & $41.30 \%$ \\
\multirow{5}{*}{ Body perception } & Pleasure & 56 & $30.43 \%$ \\
& Love & 52 & $28.26 \%$ \\
& Good looking & 62 & $50.00 \%$ \\
& Pretty & 40 & $32.26 \%$ \\
& Nice & 22 & $17.74 \%$ \\
\hline
\end{tabular}

Regression analysis of the variable self-esteem in relation to predictor variables body mass index and dimensions of selfperception. Results of the regression analysis (Table V) show that in the whole system of predictors exist statistically significant relations

Table V. Regression analysis of the variable self-esteem in relation to predictor variables body mass index and dimensions of self-perception

\begin{tabular}{lcccccc}
\hline $\mathbf{R}$ & $\mathbf{R}^{\mathbf{2}}$ & Adjusted $\mathbf{R} 2$ & St.Er.E & $\mathbf{d f}$ & $\mathbf{F}$ & $\mathbf{p}$ \\
\hline $0.74 \quad 0.54$ & 0.12 & 14.82 & 11.109 & 13.75 & 0.00 \\
Variable & B & St.Er.B. & BETA & $\mathbf{t}$ & $\mathbf{p}$ \\
(Constant) & 21.10 & 5.96 & --- & 3.54 & $\mathbf{0 . 0 0}$ \\
BMI & 0.25 & 0.17 & 0.19 & 1.40 & 0.17 \\
OSSL & -0.05 & 0.02 & -0.27 & -2.26 & 0.06 \\
OSDO & 0.05 & 0.03 & 0.20 & 1.47 & 0.15 \\
DOZT & 0.07 & 0.03 & 0.39 & 2.38 & $\mathbf{0 . 0 2}$ \\
\hline
\end{tabular}

Table VI. Regression analysis of variable body perception in relation to the predictor variables body mass index, dimensions of self-perception and selfesteem

\begin{tabular}{|c|c|c|c|c|c|c|}
\hline $\mathbf{R}$ & $\mathbf{R}^{2}$ & Adjusted $\mathbf{R}^{2}$ & St.Er.E & df & $\mathbf{F}$ & $\mathbf{p}$ \\
\hline 0.73 & 0.54 & 0.50 & 14.82 & 11.109 & 13.75 & 0.00 \\
\hline \multicolumn{2}{|c|}{ Variable } & B & St.Er.B. & BETA & t & $\mathbf{p}$ \\
\hline \multicolumn{2}{|c|}{ (Constant) } & 114.37 & 23.14 & --- & 4.94 & 0.00 \\
\hline \multicolumn{2}{|c|}{ BMI } & 0.22 & 0.15 & 0.14 & 1.20 & 0.11 \\
\hline \multicolumn{2}{|c|}{ OSSL } & -0.21 & 0.09 & -0.22 & -2.43 & 0.02 \\
\hline \multicolumn{2}{|c|}{ OSDO } & 0.55 & 0.14 & 0.38 & 4.05 & 0.00 \\
\hline \multicolumn{2}{|c|}{ RSES } & 114.37 & 23.14 & --- & 4.94 & 0.00 \\
\hline
\end{tabular}

with criterion (self - esteem) and the variable which emerged as a predictor is variable "Body perception - DOZT". Although women in the sample did not have low self-esteem, the results indicate that those patients who, in the range of results that measure self-esteem, scored higher had better self-perception of their own bodies.

Regression analysis of variable body perception in relation to the predictor variables body mass index, dimensions of selfperception and self-esteem. Regression analysis (Table VI) was conducted to investigate the influence of variables: "I feel good", "I feel poorly", "Body Mass Index" and "self-esteem" that are marked as predictor variables, to the variable body perception (DOZT) - criterion. The results show that the whole system of predictor variables is related to the criterion variable ("body perception" - DOZT), and as predictors emerged all observed variables (OSSL, OSDO, RSES), except variable Body Mass Index. Results indicate that self-esteem, self-perception and the sense of comfort and discomfort affect the body experience unrelated to body mass index.

Some researches which examined the association between BMI and self-perception found that those respondents who have a higher BMI, had lower level of self-perception (Cuddihy et al., 2006; Paxton et al., 2006). However, some of researches have shown that increased body weight is not associated with poor self-esteem and depression (Ozmen et al., 2007), but that thinness as a physical ideal, poor self-esteem and self-perception of their own bodies have significantly higher impact on dissatisfaction with appearance, then real increased physical weight (Canpolat et al., 2005). In a meta-analysis of the relationship between weight and self-esteem, Miller \& Downey (1999) reported that even in children, perceived size was a better predictor of selfesteem than was actual body weight. Some other studies have not found a strong association between overweight and self-esteem (Strauss, 2000). Young-Hyman et al. (2003), have found that relationship between obesity and selfesteem in African-American children depends upon age, gender, and children's experiences with teasing and parental evaluation of their size. 


\section{CONCLUSION}

The obtained results indicate a significant mutual influence between self-perceptions, sense of comfort related to physical appearance and self-esteem among students in the study sample, which may not be connected to the actual body weight. Predictor of higher level of self-esteem in subjects included in this study was higher level of bodyperception. Predictors of better body-perception were higher level of self-esteem, higher level of self-perception of dimension "I feel good", and lover level of self-perception of dimension "I feel bad".

BRATOVCIC, V.; MIKIC, B.; KOSTOVSKI, Z.; TESKEREDZIC, A. \& TANOVIC, I. Relaciones entre las diferentes dimensiones de la autopercepción, autoestima e índice de masa corporal de mujeres estudiantes. Int. J. Morphol., 33(4):1338-1342, 2015.

RESUMEN: Los objetivos de este estudio fueron investigar la asociación de índice de masa corporal (IMC) con diferentes dimensiones de la percepción de sí mismo y el nivel de autoestima de las estudiantes de la Universidad de Tuzla. El estudio se realizó sobre una muestra de 120 estudiantes del primer y segundo año en la Universidad de Tuzla y utilizó los siguientes instrumentos: Escala de Autoestima de Rosenberg (ROSF), Cuestionario PD forma A y cálculo del IMC. Los resultados indicaron que el autoestima y autovaloración, junto con una sensación de comodidad e incomodidad afectan la experiencia de percepción del cuerpo, sin tener relación con el IMC. También se determinaron cuales fueron variables predictoras significativas de la experiencia de percepción corporal y el nivel de autoestima en la muestra examinada, indicando una correlación significativa entre la autopercepción y la sensación de bienestar relacionadas con la imagen corporal en el autoestima de los estudiantes analizados, los cuales podrían no estar relacionados con la apariencia corporal real en términos de reducción o aumento de peso corporal.

PALABRAS CLAVE: Autopercepción; Índice de masa corporal; Autoestima; Estudiantes.

\section{REFERENCES}

Canpolat, B. I.; Orsel, S.; Akdemir, A. \& Ozbay, M. H. The relationship between dieting and body image, body ideal, self-perception, and body mass index in Turkish adolescents. Int. J. Eat Disord., 37(2):150-5, 2005.

Chang, V. W. \& Christakis, N. A. Self-perception of weight appropriateness in the United States. Am. J. Prev. Med., 24(4):332-9, 2003.

Cuddihy, T.; Tomson, L. M.; Jones, E. K. \& Johnston, A. O. Exploring the relationship between daily steps, body mass index and physical self-esteem in female Australian adolescents. J. Exerc. Sci. Fit., 4(1):25-35, 2006.

Klaczynski, P. A.; Goold, K. W. \& Mudry, J. J. Culture, obesity stereotypes, self-esteem, and the "thin ideal": A social identity perspective. J. Youth Adolesc., 33(4):307-17, 2004.

Lackovic-Grgin, K. Samopouzdanje mladih. Jastrebarsko, Naklada Slap, 1994.

Miller, C. T., \& Downey, K. T. A meta-analysis of heavyweight and selfesteem. Pers. Soc. Psychol. Rev., 3(1):68-84, 1999.

O'Dea, J. A. \& Abraham, S. Association between self-concept and body weight, gender, and pubertal development among male and female adolescents. Adolescence,34(133):69-79, 1999.

Ozmen, D.; Ozmen, E.; Ergin, D.; Cetinkaya, A. C.; Sen, N.; Dundar, P. E. \& Taskin, E. O. The association of self-esteem, depression and body satisfaction with obesity among Turkish adolescents. BMC Public Health, 7:80, 2007.

Paxton, S. J.; Neumark-Sztainer, D.; Hannan, P. J. \& Eisenberg, M. E. Body dissatisfaction prospectively predicts depressive mood and low selfesteem in adolescent girls and boys. J. Clin. Child. Adolesc. Psychol., 35(4):539-49, 2006.

Pokrajac-Bulian, A. \& Zivcic-Becirevic, I. Locus of control and self-esteem as correlates of body dissatisfaction in Croatian university students. Eur. Eat. Disord. Rev., 13(1):54-60, 2005.
Pritchard, M. E.; King, S. L. \& Czajka-Narins, D. M. Adolescent body mass indices and self-perception. Adolescence, 32(128):863-80, 1997.

Prstacic, M. \& Hrastovec, D. Ekstazaigeneza Ekstaza i geneza: znanost, umjetnost $i$ kreativna terapija u psihosocijalnoj onkologiji i sofrologiji = Extase et genèse: la science, l'art et la thérapie créative en oncologie psychosociale et sophrologie $=$ Ecstasy and genesis : science, art and creative therapy in psychosocial oncology and sophrology. Zagreb, Medicinska Knjiga, 2003.

Rosenberg, M. Society and the adolescent self-image. Princeton, Princeton University Press, 1965.

Rosenberg, M.; Schooler, C.; Schoenbach, C. \& Rosenberg, F. Global selfesteem and specific self-esteem: Different concepts, different outcomes. Am. Sociol. Rev., 60(1):141-56, 1995.

Slade, P. D. What is body image? Behav. Res. Ther, 32(5):497-502, 1994.

Strauss, R. S. Childhood obesity and self-esteem. Pediatrics, 105(1):e15, 2000.

Young-Hyman, D.; Schlundt, D. G.; Herman-Wenderoth, L. \& Bozylinski, K. Obesity, appearance, and psychosocial adaptation in young African American children. J. Pediatr. Psychol., 28(7):463-72, 2003.

Correspondence to:

Zarko Kostovski

University Ss. Cyril and Methodius

Faculty of Physical Culture

Sport and Health

Skopje

REPUBLIC OF MACEDONIA

Email: zarkok@ukim.edu.mk

Received: 10-01-2015

Accepted: 08-10-2015 